\title{
Longterm (52-week) Results of a Phase III Randomized, Controlled Trial of Apremilast in Patients with Psoriatic Arthritis
}

\author{
Arthur Kavanaugh, Philip J. Mease, Juan J. Gomez-Reino, Adewale O. Adebajo, \\ Jürgen Wollenhaupt, Dafna D. Gladman, Marla Hochfeld, Lichen L. Teng, Georg Schett, \\ Eric Lespessailles, and Stephen Hall
}

\begin{abstract}
Objective. To evaluate the efficacy and safety of apremilast, an oral phosphodiesterase 4 inhibitor, over 52 weeks in patients with active psoriatic arthritis (PsA) despite prior treatment.

Methods. Patients were randomized to placebo $(\mathrm{n}=168)$, apremilast $20 \mathrm{mg}$ BID $(\mathrm{n}=168)$, or apremilast $30 \mathrm{mg}$ BID $(\mathrm{n}=168)$. Patients whose swollen and tender joint counts had not improved by $\geq 20 \%$ at Week 16 were considered nonresponders and were required to be re-randomized (1:1) to apremilast $20 \mathrm{mg}$ BID or $30 \mathrm{mg}$ BID if they were initially randomized to placebo, or continued their initial treatment of apremilast dose. At Week 24, all remaining patients treated with placebo were re-randomized to apremilast $20 \mathrm{mg}$ BID or $30 \mathrm{mg}$ BID.

Results. An American College of Rheumatology 20 (ACR20) response at Week 16 was attained by significantly more patients receiving apremilast $20 \mathrm{mg}$ BID $(30.4 \%, \mathrm{p}=0.0166)$ or $30 \mathrm{mg}$ BID $(38.1 \%, \mathrm{p}=0.0001)$ than placebo $(19.0 \%)$. Among patients receiving apremilast continuously for 52 weeks $(\mathrm{n}=254)$, ACR20 response at Week 52 was observed in 63.0\% $(75 / 119,20 \mathrm{mg}$ BID) and $54.6 \%$ (71/130, $30 \mathrm{mg}$ BID) of patients. Response was also maintained across secondary outcomes, including measures of PsA signs and symptoms, skin psoriasis severity, and physical function. The nature, incidence, and severity of adverse events were comparable over the 24-week and 52-week periods. The most common adverse events, diarrhea and nausea, generally occurred early and were self-limited.

Conclusion. Continuous apremilast treatment resulted in sustained improvements in PsA for up to 52 weeks. Apremilast had an acceptable safety profile and was generally well tolerated. Clinical trial registration: NCT01172938. (First Release Jan 15 2015; J Rheumatol 2015;42:479-88; doi:10.3899/ jrheum.140647)
\end{abstract}

\section{Key Indexing Terms:} APREMILAST PHOSPHODIESTERASE 4 INHIBITOR

PSORIATIC ARTHRITIS SAFETY TREATMENT EFFICACY

Apremilast is an oral phosphodiesterase 4 inhibitor that works intracellularly to regulate inflammatory mediators ${ }^{1}$. The efficacy, safety, and tolerability of apremilast are being evaluated in patients with active psoriatic arthritis (PsA) in the Psoriatic Arthritis Longterm Assessment of Clinical

From the University of California, San Diego School of Medicine, La Jolla, California; Swedish Medical Center and University of Washington School of Medicine, Seattle, Washington; Celgene Corporation, Summit, New Jersey, USA; University of Sheffield, Sheffield, UK; Hospital Clinico Universitario, Santiago, Spain; Schön Klinik Hamburg Eilbek, Hamburg, University of Erlangen-Nuremberg, Erlangen, Germany; Toronto Western Research Institute, Toronto, Ontario, Canada; University of Orléans, Orléans, France; and the Monash University, Cabrini Health Australia, Melbourne, Australia.

Supported by Celgene Corporation. Dr. Kavanaugh has provided expert advice to and/or received research grants from Celgene Corporation. Dr. Mease, Dr. Gladman, and Dr. Schett have received research grants and consultant fees from Celgene Corporation. Dr. Hochfeld is an employee of Celgene Corporation. Dr. Teng is a consultant for Celgene Corporation.

A. Kavanaugh, MD, Division of Rheumatology, Allergy and Immunology, University of California; P.J. Mease, MD, Swedish Hospital Clinical Research Division, Swedish Medical Center, and Clinical Professor, University of Washington School of Medicine; J.J. Gomez-Reino, MD,
Efficacy (PALACE) phase III clinical trial program, which is composed of 4 randomized, placebo-controlled studies with open-label extensions conducted globally. PALACE 1 assessed the efficacy and safety of apremilast $20 \mathrm{mg}$ BID or $30 \mathrm{mg}$ BID in patients with active PsA despite conventional

PhD, Rheumatology Service, Department of Medicine, Hospital Clinico Universitario; A.O. Adebajo, MD, FRCP, Professor of Rheumatology, Faculty of Medicine, Dentistry and Health, University of Sheffield; Prof. Dr. med. J. Wollenhaupt, Schön Klinik Hamburg Eilbek, Klinik für Rheumatologie; D.D. Gladman, MD, FRCPC, Division of Health Care and Outcomes Research, Toronto Western Research Institute;

M. Hochfeld, MD; L.L. Teng, PhD, Celgene Corporation; Prof. Dr. med. $G$. Schett, Department of Internal Medicine, University of Erlangen-Nuremberg; E. Lespessailles, MD, PhD, University of Orléans; S. Hall, MBBS, FRACP, Associate Professor of Medicine, Monash University, Cabrini Health Australia.

Address correspondence to Dr. A. Kavanaugh, Division of Rheumatology, Allergy and Immunology, Department of Medicine, University of California, San Diego, 9500 Gilman Drive, Mail Code 0943, La Jolla, California 92093-0942,USA.E-mail: akavanaugh@ucsd.edu Full Release Article. For details see Reprints/Permissions at jrheum.org Accepted for publication October 20, 2014.

Personal non-commercial use only. The Journal of Rheumatology Copyright (c) 2015. All rights reserved. 
disease-modifying antirheumatic drug (DMARD) and/or biologic therapy, including tumor necrosis factor blocker therapeutic failures. Results from the placebo-controlled phase of PALACE 1 have previously been reported ${ }^{2}$. The current report described the results from the longterm (52-week), randomized, double-blind, active treatment phase.

\section{MATERIALS AND METHODS}

Study design. PALACE 1 was a phase III, randomized, placebo-controlled study (ClinicalTrials.gov, NCT01172938). The study design and methodology of the 24-week, placebo-controlled phase have been reported elsewhere ${ }^{2}$. Eligible patients were randomized (1:1:1) to placebo, apremilast $20 \mathrm{mg}$ BID, or apremilast $30 \mathrm{mg}$ BID stratified by baseline DMARD use (yes/no). Patients whose swollen and tender joint counts had not improved by $\geq 20 \%$ at Week 16 were considered nonresponders and were required to be re-randomized (1:1) to apremilast $20 \mathrm{mg}$ BID or $30 \mathrm{mg}$ BID if they were initially randomized to placebo, or continued their initial treatment of apremilast dose. At Week 24, all remaining placebo patients were re-randomized to apremilast $20 \mathrm{mg}$ BID or $30 \mathrm{mg}$ BID.

Study population. Eligible patients included adults who had a diagnosis of PsA for 6 months or longer, who fulfilled the Classification Criteria for Psoriatic Arthritis, and upon examination, had 3 or more swollen and 3 or more tender joints, despite previous treatment with conventional DMARD and/or biologic agents. Concurrent treatment with stable doses of methotrexate (MTX; $\leq 25 \mathrm{mg} /$ week), leflunomide ( $\leq 20 \mathrm{mg} /$ day), sulfasalazine ( $\leq 2 \mathrm{~g} /$ day), or a combination was allowed, as were oral corticosteroids (prednisone $\leq 10 \mathrm{mg} /$ day or equivalent for $1 \mathrm{mo}$ before baseline) and nonsteroidal antiinflammatory drugs ( $\geq 2$ weeks before baseline).

The institutional review boards of the participating medical centers approved the protocol. All patients provided written informed consent before the conduct of any study-related procedures.

Statistical analysis. Statistical analyses for the placebo-controlled period have been reported $^{2}$. In this report, efficacy analyses for the active treatment phase included all patients exposed to apremilast from the first dose and also completing treatment through Week 52. Data as observed were summarized for each group according to the treatment assigned at randomization (baseline) or re-randomization (weeks 16 or 24). These analyses were conducted using the data available at each timepoint with no imputation for missing data. Efficacy data were summarized using descriptive statistics for the continuous variable, and counts and percentages for binary variables. Two-sided $95 \%$ CI of mean change and percent change from baseline for continuous variables, and of proportions for binary variables, were provided for each treatment group.

Safety data were analyzed among the safety population, which included all randomized patients who received $\geq 1$ dose of study medication. Data were analyzed for (1) the placebo-controlled period, which included data through Week 16 for placebo patients who escaped early and data through Week 24 for all other patients, and (2) the apremilast-exposure period, which included data for all patients who received $\geq 1$ dose of apremilast regardless of when apremilast was initiated. Safety outcomes were summarized descriptively, including adverse events (AE) classified using the Medical Dictionary for Drug Regulatory Activities classification system, laboratory data, and vital sign measurements.

\section{RESULTS}

Patients. At baseline, 504 patients were randomized and 444 (88.1\%) completed 24 weeks (placebo-controlled phase; Figure 1). At Week 24, 428 patients entered the active treatment period. Of those patients, $373(87.1 \%)$ completed 52 weeks, including 124/168 (73.8\%) initially randomized to apremilast $20 \mathrm{mg}$ BID and 130/168 (77.4\%) initially randomized to apremilast $30 \mathrm{mg}$ BID at baseline.

Patients' demographics, disease history, and prior or concurrent therapy were comparable at baseline among treatment groups and reflective of a population with active PsA (Appendix 1) ${ }^{2}$. At baseline, $64.9 \%$ of patients were receiving conventional DMARD, and $54.2 \%$ were receiving MTX. Overall, $23.6 \%$ of patients had prior exposure to biologic agents and $9.3 \%$ had therapeutic failure to biologic therapy.

Efficacy. At Week 16, a significantly greater proportion of patients receiving apremilast $20 \mathrm{mg}$ BID $(30.4 \%, \mathrm{p}=$ $0.0166)$ or $30 \mathrm{mg}$ BID $(38.1 \%, \mathrm{p}=0.0001)$ achieved a modified American College of Rheumatology 20 (ACR20) response compared with placebo $(19.0 \%)^{2}$. Among the patients who continued receiving treatment with apremilast through Week 52, rates of ACR20 response were sustained over 52 weeks (Figure 2). At Week 52,63.0\% of patients who received apremilast $20 \mathrm{mg}$ BID from baseline and $54.6 \%$ who received $30 \mathrm{mg}$ BID achieved an ACR20 (Table 1). ACR50 and ACR70 responses were observed in $24.8 \%$ and $15.4 \%$ of patients receiving apremilast $20 \mathrm{mg}$ BID and $24.6 \%$ and $13.8 \%$ of patients receiving apremilast $30 \mathrm{mg}$ BID, respectively (Table 1, Figure 3). Placebo patients who were re-randomized to apremilast at weeks 16 or 24 demonstrated results consistent with patients randomized to apremilast at baseline (Figure 2). Health Assessment Questionnaire-Disability Index (HAQ-DI) scores were also maintained in both apremilast groups over 52 weeks with continued treatment (Figure 4). At Week 52, mean (SD) reductions in HAQ-DI score were $-0.37(0.48)$ with apremilast $20 \mathrm{mg}$ BID and $-0.32(0.55)$ with apremilast 30 $\mathrm{mg}$ BID, with improvements of $\geq 0.13$ observed in $60.0 \%$ and $59.8 \%$, respectively, and improvements of $\geq 0.30$ observed in $45.8 \%$ and $44.7 \%$, respectively.

The therapeutic effect of apremilast was maintained across several other measures of efficacy through Week 52 in those patients continuing the therapy (Table 1, Appendix 2). Decreases in disease activity of PsA, as demonstrated by reductions in both the swollen and tender joint counts, 28-joint count Disease Activity Score (C-reactive protein), and Clinical Disease Activity Index score, as well as the achievement of a good or moderate European League Against Rheumatism response, were sustained. Improvements in other physical function measures were also maintained: the 36-item Medical Outcomes Study Short Form-36 health survey version 2 (SF-36v2) Physical Functioning domain, health-related quality of life (SF-36v2 physical component summary and Functional Assessment of Chronic Illness Therapy-Fatigue), and patient assessment of pain.

In patients with enthesitis and dactylitis at baseline who received apremilast continuously through Week 52, the median percent change from baseline in Maastricht Anky-

Personal non-commercial use only. The Journal of Rheumatology Copyright (C) 2015. All rights reserved 


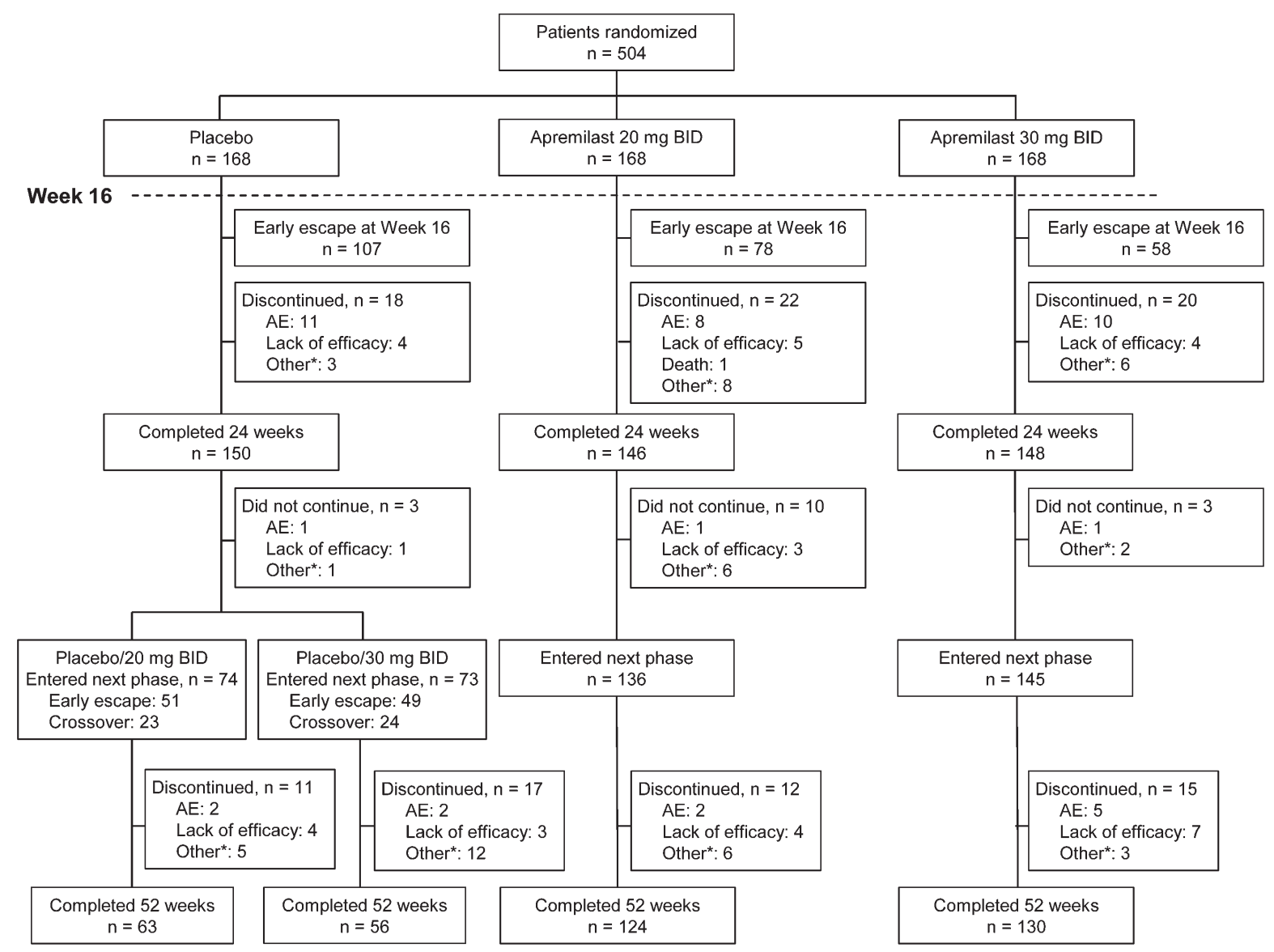

Figure 1. Patient disposition. * Includes withdrawal by patient, loss to followup, protocol violation, noncompliance, and other. Patients who discontinued apremilast were encouraged to complete scheduled study assessments. AE: adverse event.

losing Spondylitis Enthesitis Score (MASES) at Week 52 was $100 \%$ with apremilast $20 \mathrm{mg}$ BID and $66.7 \%$ with apremilast $30 \mathrm{mg} \mathrm{BID}$, and a MASES score of 0 was observed in $50.7 \%(35 / 69)$ of patients receiving apremilast $20 \mathrm{mg}$ BID and $38.2 \%(34 / 89)$ receiving apremilast $30 \mathrm{mg}$ BID at Week 52. The median percent change in dactylitis count was $100 \%$ in patients receiving apremilast $20 \mathrm{mg}$ BID or $30 \mathrm{mg}$ BID from baseline, and a dactylitis score of 0 was observed in $68.8 \%(33 / 48)$ of patients receiving apremilast $20 \mathrm{mg}$ BID and 63.3\% (31/49) receiving apremilast $30 \mathrm{mg}$ BID from baseline.

Among patients initially randomized to apremilast at baseline who had a psoriasis body surface area $\geq 3 \%$ and were followed through Week $52(\mathrm{n}=121)$, a 50\% reduction from the baseline Psoriasis Area and Severity Index (PASI) score was observed in $52.8 \%$ of patients receiving apremilast $20 \mathrm{mg}$ BID and $60.3 \%$ receiving apremilast $30 \mathrm{mg}$ BID at Week 52; a 75\% reduction from baseline PASI score was observed in $24.5 \%$ of patients receiving apremilast $20 \mathrm{mg}$ BID and 36.8\% receiving apremilast $30 \mathrm{mg}$ BID (Table 1).

Across the 52-week apremilast-exposure period, patients initially randomized to placebo and then re-randomized to apremilast at weeks 16 or 24 demonstrated results consistent with patients randomized to apremilast at baseline (Table 1), although no placebo group was available for comparison.

Safety and tolerability. During the placebo-controlled period (weeks 0 to 24), exposure to apremilast was 57.0 (placebo), 72.0 (apremilast $20 \mathrm{mg}$ BID), and 70.9 (apremilast $30 \mathrm{mg}$ BID) patient-years (total number of yrs exposed to study medication for all patients). During the apremilast-exposure period (weeks 0 to 52), exposure to apremilast was 185.6 (20 mg BID) and 185.5 (30 mg BID) patient-years. Table 2 provides an overview of AE during the 24-week placebo-controlled and 52-week apremilast-exposure periods. Most AE occurred during the first 24 weeks, in which about $50 \%$ of placebo patients and about $60 \%$ of patients treated with apremilast reported $\geq 1 \mathrm{AE}$. AE occurring in $\geq 5 \%$ of any treatment group were diarrhea, nausea, headache, upper respiratory tract infection, and nasopharyngitis (Table 2). The nature, incidence, and severity of AE were comparable over the 24-week and 52 -week periods. Most AE (>90\%) were mild to moderate in severity, and discontinuation rates because of $\mathrm{AE}$ (weeks 0 to 52 ) were $<10 \%$ (Table 2).

In patients receiving apremilast, diarrhea and nausea were most often reported during the first 2 weeks of 


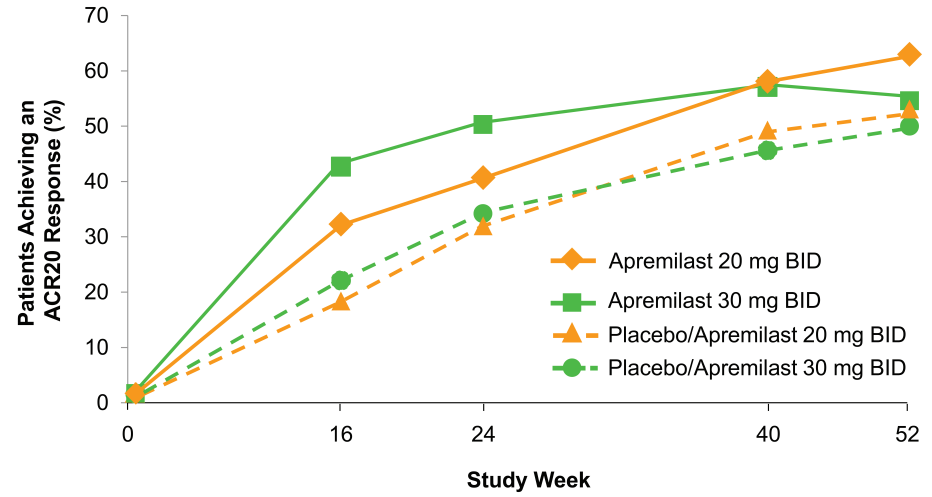

\begin{tabular}{|l|c|c|c|c|}
\hline Apremilast $20 \mathrm{mg} \mathrm{BID}, \mathrm{n} / \mathrm{m}$ & $51 / 158$ & $59 / 145$ & $75 / 129$ & $75 / 119$ \\
\hline Apremilast $30 \mathrm{mg} \mathrm{BID,} \mathrm{n} / \mathrm{m}$ & $64 / 150$ & $73 / 145$ & $80 / 140$ & $71 / 130$ \\
\hline Placebo/Apremilast 20 mg BID, $\mathrm{n} / \mathrm{m}$ & $14 / 76$ & $24 / 75$ & $34 / 69$ & $34 / 64$ \\
\hline Placebo/Apremilast $30 \mathrm{mg}$ BID, $\mathrm{n} / \mathrm{m}$ & $17 / 77$ & $26 / 76$ & $31 / 68$ & $30 / 60$ \\
\hline
\end{tabular}

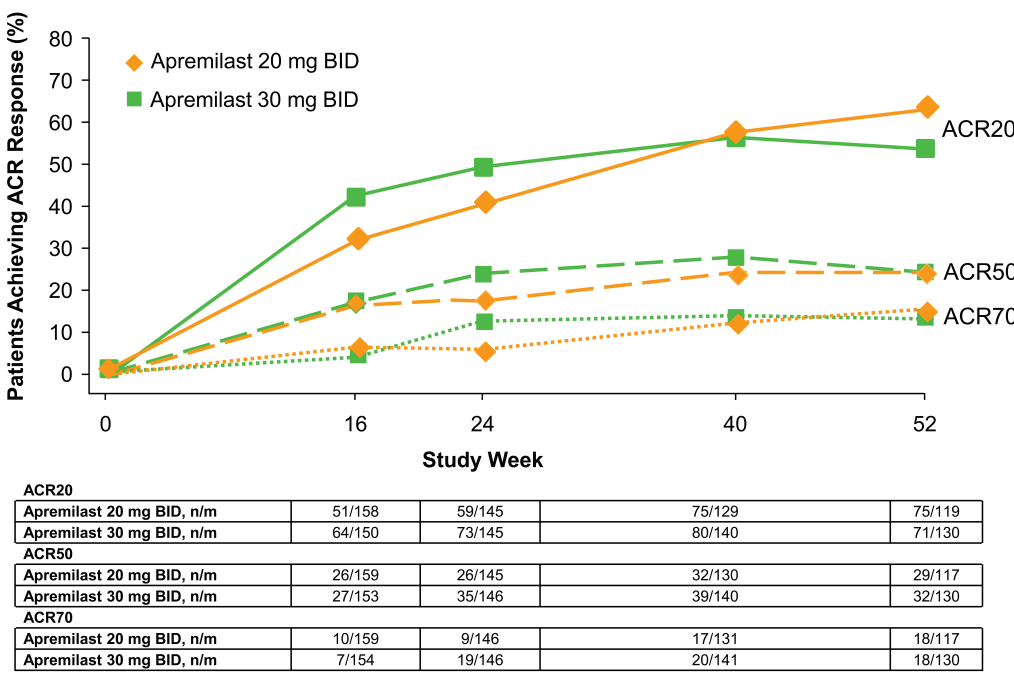

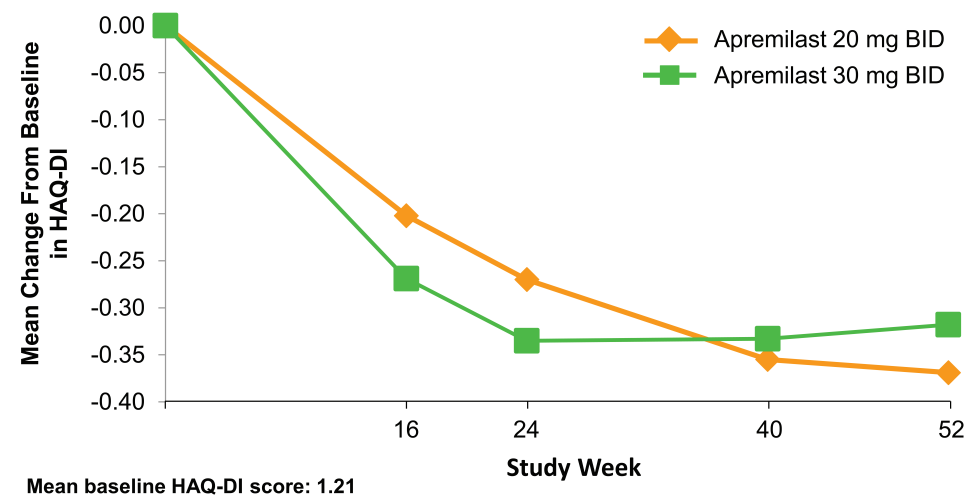

\begin{tabular}{|l|l|l|l|l|}
\hline Apremilast $20 \mathrm{mg}$ BID, $\mathrm{n}$ & 160 & 147 & 131 & 120 \\
\hline Apremilast $30 \mathrm{mg}$ BID, $\mathrm{n}$ & 151 & 146 & 141 & 132 \\
\hline
\end{tabular}

Figure 2. Proportion of patients achieving ACR20 response over 52 weeks. ACR20: American College of Rheumatology 20\% improvement; n/m: number of responders/number of patients with sufficient data for evaluation

Figure 3. Proportion of patients receiving apremilast from baseline who achieved ACR20/50/70 over 52 weeks. ACR20/50/70: American College of Rheumatology \% of improvement; $\mathrm{n} / \mathrm{m}$ : number of responders/number of patients with sufficient data for evaluation.

Figure 4. Mean change from baseline in HAQ-DI over 52 weeks in patients receiving apremilast from baseline HAQ-DI: Health Assessment Questionnaire-Disability Index. 
Table 1. Efficacy endpoints at Week 52*. The $\mathrm{n}$ reflects the no. patients who completed 52 weeks; actual no. patients available for each endpoint may vary. Values are $\mathrm{n} / \mathrm{m}(\%)$ or mean change (SD) unless otherwise specified.

\begin{tabular}{|c|c|c|c|c|}
\hline Characteristics & $\begin{array}{l}\text { Placebo/Apremilast } \\
20 \mathrm{mg} \text { BID, } \mathrm{n}=63\end{array}$ & $\begin{array}{l}\text { Placebo/Apremilast } \\
30 \mathrm{mg} \text { BID, } \mathrm{n}=56\end{array}$ & $\begin{array}{c}\text { Apremilast } \\
20 \mathrm{mg} \mathrm{BID}, \mathrm{n}=124\end{array}$ & $\begin{array}{c}\text { Apremilast } \\
30 \mathrm{mg} \text { BID, } \mathrm{n}=130\end{array}$ \\
\hline ACR20 & 34/64 (53.1) & $30 / 60(50.0)$ & 75/119 (63.0) & 71/130 (54.6) \\
\hline ACR70 & $3 / 62(4.8)$ & 9/61 (14.8) & $18 / 117(15.4)$ & $18 / 130(13.8)$ \\
\hline HAQ-DI, 0-3 & $-0.27(0.56)$ & $-0.29(0.59)$ & $-0.37(0.48)$ & $-0.32(0.55)$ \\
\hline SF-36v2 $\mathrm{PF}^{\S}$ & $4.5(8.9)$ & $4.6(10.0)$ & $7.0(9.4)$ & $5.7(9.0)$ \\
\hline EULAR good/moderate response & $53 / 64(82.8)$ & $42 / 60(70.0)$ & $90 / 120(75.0)$ & $96 / 129(74.4)$ \\
\hline mPsARC response & $45 / 61(73.8)$ & $42 / 59(71.2)$ & $93 / 120(77.5)$ & $95 / 129(73.6)$ \\
\hline DAS28, CRP & $-1.5(1.1)$ & $-1.2(1.3)$ & $-1.4(1.1)$ & $-1.3(1.1)$ \\
\hline DAS28, CRP,$<2.6$ & $17 / 65(26.2)$ & $11 / 60(18.3)$ & $39 / 120(32.5)$ & $30 / 129(23.3)$ \\
\hline CDAI, 0-76 & $-15.0(11.1)$ & $-14.0(14.9)$ & $-15.4(13.0)$ & $-14.5(12.0)$ \\
\hline MASES, $0-13$, median $\%$ change c $^{\ddagger}$ & -50.0 & -40.0 & -100.0 & -66.7 \\
\hline Patient global assessment, $0-100$ VAS, median $\%$ change & -38.5 & -22.1 & -36.8 & -28.6 \\
\hline Physician global assessment, $0-100$ VAS, median $\%$ change & -70.9 & -58.8 & -66.7 & -61.7 \\
\hline Patient assessment of pain, $0-100$ VAS, median $\%$ change & -33.6 & -37.9 & -35.6 & -30.9 \\
\hline PASI-50 & $11 / 25(44.0)$ & $11 / 27(40.7)$ & $28 / 53(52.8)$ & $41 / 68(60.3)$ \\
\hline PASI-75 & $4 / 25(16.0)$ & $6 / 27(22.2)$ & $13 / 53(24.5)$ & $25 / 68(36.8)$ \\
\hline
\end{tabular}

* Data as observed. Based on patients randomized to apremilast, placebo/apremilast $20 \mathrm{mg}$ BID and placebo/apremilast $30 \mathrm{mg}$ BID groups include patients who were randomized to placebo at baseline and re-randomized to apremilast $20 \mathrm{mg}$ BID and apremilast $30 \mathrm{mg}$ BID, respectively, at weeks 16 or 24 ; apremilast $20 \mathrm{mg}$ BID and apremilast $30 \mathrm{mg}$ BID groups include patients randomized to the respective regimen at baseline. ${ }^{\S}$ Increase indicates improvement. ¥ Examined among patients with enthesitis at baseline and having data at Week 52 (placebo/apremilast $20 \mathrm{mg}$ BID: $\mathrm{n}=36$; placebo/apremilast $30 \mathrm{mg}$ BID: $\mathrm{n}=36$; apremilast $20 \mathrm{mg}$ BID: $\mathrm{n}=69$; apremilast 30 mg BID: $\mathrm{n}=89$ ). " Examined among patients with dactylitis at baseline and having data at Week 52 (placebo/apremilast $20 \mathrm{mg}$ BID: $\mathrm{n}=23$; placebo/apremilast $30 \mathrm{mg}$ BID: $\mathrm{n}=26$; apremilast $20 \mathrm{mg}$ BID: $\mathrm{n}=48$; apremilast $30 \mathrm{mg}$ BID: $\mathrm{n}=49$ ). ${ }^{9}$ Examined among patients with psoriasis involving body surface area $\geq 3 \%$ at baseline. $\mathrm{n} / \mathrm{m}$ : number of responders/number of patients with sufficient data for evaluation. ACR20/50/70: 20\%/50\%/70\% improvement in modified American College of Rheumatology response criteria; HAQ-DI: Health Assessment Questionnaire-Disability Index; SF-36v2 PF: Medical Outcomes Study Short Form-36 health survey version 2 Physical Functioning domain; PCS: physical component summary score; FACIT-Fatigue: Functional Assessment of Chronic Illness Therapy-Fatigue; EULAR: European League Against Rheumatism; mPsARC: modified psoriatic arthritis response criteria; DAS28: 28-joint Disease Activity Score (using CRP as acute-phase reactant); CRP: C-reactive protein; CDAI: Clinical Disease Activity Index; MASES: Maastricht Ankylosing Spondylitis Enthesitis Score; VAS: visual analog scale; PASI-50/75: 50\%/75\% reduction from baseline Psoriasis Area and Severity Index score.

treatment and usually resolved in 4 weeks without medicinal intervention and despite continued treatment. Overall, $<2 \%$ of patients who received apremilast discontinued because of diarrhea or nausea through 52 weeks. In patients receiving apremilast over 52 weeks, new reports of diarrhea and nausea were rare between weeks 24 and 52 with either dose (20 mg BID: diarrhea $n=2$, nausea $n=5 ; 30 \mathrm{mg}$ BID: diarrhea $n=3$, nausea $n=2$ ). No cases of diarrhea were reported as a serious AE (SAE) up to Week 52. One SAE of nausea was reported in a patient receiving apremilast $30 \mathrm{mg}$ BID during the placebo-controlled phase. No additional SAE of nausea were reported up to Week 52.

SAE occurred infrequently during both treatment periods, and the incidence was comparable across treatment groups (Table 2). No individual SAE was reported by $>1$ patient per treatment group during the 52-week treatment period, with the exception of acute myocardial infarction, which was reported in 2 male patients receiving apremilast
$20 \mathrm{mg}$ BID. One patient experienced an acute myocardial infarction on Study Day 231. He received placebo in the placebo-controlled phase, followed by apremilast $20 \mathrm{mg}$ BID for 62 days. The other patient received apremilast 20 mg BID for 39 days and experienced an acute myocardial infarction on Study Day 39. Both acute myocardial infarctions were considered possible major adverse cardiac events and occurred in patients who had a history of hyperlipidemia and smoking. In addition, these 2 patients reported either a familial history of coronary artery disease or fatal myocardial infarction, respectively; neither acute myocardial infarction was considered related to study treatment. Among patients receiving apremilast from baseline, $5 \mathrm{SAE}$ occurred during weeks 24 to 52 (endometriosis and appendicitis in 1 patient each with apremilast $20 \mathrm{mg}$ BID; gastroenteritis, myocardial infarction, and osteoarthritis in 1 patient each with apremilast $30 \mathrm{mg}$ BID). Of the 5 infections reported as SAE during the 52-week period, 2 occurred Personal non-commercial use only. The Journal of Rheumatology Copyright $\subset$ $~ 2015$. All rights reserved. 
Table 2. AE during the 24-week placebo-controlled and 52-week apremilast-exposure periods. Placebo-controlled period includes data through Week 16 for patients initially receiving placebo who escaped, and data through Week 24 for all other patients. Apremilast-exposure period includes all apremilast-exposure data, regardless of when the apremilast exposure started (weeks 0,16 , or 24).

\begin{tabular}{|c|c|c|c|c|c|}
\hline \multirow[t]{2}{*}{ Characteristics } & \multicolumn{3}{|c|}{ Weeks 0 to 24} & \multicolumn{2}{|c|}{$\begin{array}{c}\text { Weeks } 0 \text { to } 52 \\
\text { Apremilast }\end{array}$} \\
\hline & Placebo, $n=168$ & $20 \mathrm{mg}$ BID, $\mathrm{n}=168$ & $30 \mathrm{mg}$ BID, $\mathrm{n}=168$ & $20 \mathrm{mg}$ BID, $\mathrm{n}=245$ & $30 \mathrm{mg}$ BID, $\mathrm{n}=245$ \\
\hline \multicolumn{6}{|l|}{ Patients, n (\%) } \\
\hline$\geq 1 \mathrm{AE}$ & $81(48.2)$ & $101(60.1)$ & $103(61.3)$ & $164(66.9)$ & $174(71.0)$ \\
\hline Any serious AE & $7(4.2)$ & $8(4.8)$ & $9(5.4)$ & $14(5.7)$ & $19(7.8)$ \\
\hline Any severe AE & $6(3.6)$ & $8(4.8)$ & $11(6.5)$ & $15(6.1)$ & $15(6.1)$ \\
\hline AE leading to drug withdrawal & $8(4.8)$ & $10(6.0)$ & $12(7.1)$ & $16(6.5)$ & $23(9.4)$ \\
\hline Death & $0(0.0)$ & $1(0.6)^{*}$ & $0(0.0)$ & $1(0.4)$ & $0(0.0)$ \\
\hline \multicolumn{6}{|c|}{ Frequent $\mathrm{AE}, \geq 5 \%$ in any treatment group, $\mathrm{n}(\%)$} \\
\hline Diarrhea & $4(2.4)$ & $19(11.3)$ & $32(19.0)$ & $27(11.0)$ & $47(19.2)$ \\
\hline Nausea & $11(6.5)$ & $16(9.5)$ & $31(18.5)$ & $24(9.8)$ & $35(14.3)$ \\
\hline Headache & $8(4.8)$ & $17(10.1)$ & $18(10.7)$ & $22(9.0)$ & $24(9.8)$ \\
\hline URTI & $6(3.6)$ & $10(6.0)$ & $7(4.2)$ & $19(7.8)$ & $14(5.7)$ \\
\hline Nasopharyngitis & $5(3.0)$ & $6(3.6)$ & $8(4.8)$ & $17(6.9)$ & $16(6.5)$ \\
\hline \multicolumn{6}{|l|}{ Select laboratory assessments } \\
\hline \multicolumn{6}{|l|}{ Marked abnormalities, $\mathrm{n} / \mathrm{m}(\%)^{\S}$} \\
\hline $\mathrm{ALT}>150 \mathrm{U} / 1$ & $0 / 167(0.0)$ & $0 / 166(0.0)$ & 2/168 (1.2) & $0 / 243(0.0)$ & $2 / 245(0.8)$ \\
\hline $\begin{array}{l}\text { Creatinine, male }>156 \text {, female } \\
\quad>126 \mu \mathrm{mol} / 1\end{array}$ & $0 / 167(0.0)$ & $1 / 166(0.6)$ & $0 / 168(0.0)$ & $1 / 243(0.4)$ & $0 / 245(0.0)$ \\
\hline \multicolumn{6}{|c|}{$\begin{array}{l}\text { Hemoglobin, male: decrease }>2.0 \text { and } \\
\text { value }<10.5 \mathrm{~g} / \mathrm{dl} \text {; female: decrease }\end{array}$} \\
\hline$>2.0$ and value $<10.0 \mathrm{~g} / \mathrm{dl}$ & $0 / 167(0.0)$ & $0 / 166(0.0)$ & $1 / 168(0.6)$ & $0 / 243(0.0)$ & $2 / 245(0.8)$ \\
\hline Leukocytes $<2.0,10^{9} / 1$ & $0 / 167(0.0)$ & $0 / 166(0.0)$ & $0 / 168(0.0)$ & $0 / 243(0.0)$ & $0 / 245(0.0)$ \\
\hline Neutrophils $<0.75,10^{9} / 1$ & $0 / 167(0.0)$ & $0 / 166(0.0)$ & $0 / 168(0.0)$ & $0 / 243(0.0)$ & $0 / 245(0.0)$ \\
\hline Platelets $<75,10^{9} / 1$ & $0 / 166(0.0)$ & $0 / 166(0.0)$ & $0 / 168(0.0)$ & $0 / 243(0.0)$ & $0 / 245(0.0)$ \\
\hline \multicolumn{6}{|c|}{ Select laboratory shifts from normal to > upper limit of normal, $\mathrm{n} / \mathrm{m}(\%)^{\S}$} \\
\hline ALT, U/1 & $20 / 150(13.3)$ & $12 / 146(8.2)$ & $12 / 155(7.7)$ & 29/215 (13.5) & 28/222 (12.6) \\
\hline Creatinine, $\mu \mathrm{mol} / 1$ & $3 / 159(1.9)$ & $7 / 151(4.6)$ & $10 / 158(6.3)$ & $14 / 222(6.3)$ & $16 / 228(7.0)$ \\
\hline \multicolumn{6}{|c|}{ Select laboratory shifts from normal to < lower limit of normal, $\mathrm{n} / \mathrm{m}(\%)^{\S}$} \\
\hline Leukocytes, $10^{9} / 1$ & $1 / 155(0.6)$ & 4/155 (2.6) & $2 / 159(1.3)$ & $5 / 227(2.2)$ & $6 / 232(2.6)$ \\
\hline Neutrophils, $10^{9} / 1$ & 2/146 (1.4) & 2/145 (1.4) & $5 / 151(3.3)$ & 3/213 (1.4) & $8 / 221(3.6)$ \\
\hline Platelets, $10^{9} / 1$ & $0 / 146(0.0)$ & $0 / 142(0.0)$ & $1 / 151(0.7)$ & $1 / 208(0.5)$ & $1 / 221(0.5)$ \\
\hline Hemoglobin, g/dl & $8 / 148(5.4)$ & $7 / 149(4.7)$ & $14 / 153(9.2)$ & $22 / 220(10.0)$ & 26/224 (11.6) \\
\hline
\end{tabular}

* Multiorgan failure considered by investigator to be unrelated to study medication. ${ }^{\S}$ Represents patients with $\geq 1$ occurrence of the abnormality ( $\mathrm{n}$ )/patients with a baseline value of normal and $\geq 1$ post-baseline value for criteria requiring baseline or with $\geq 1$ post-baseline value for criteria requiring baseline ( $\mathrm{m}$ ). AE: adverse event; URTI: upper respiratory tract infection; ALT: alanine transaminase.

during the first 24 weeks (1 case each of pneumonia and gastrointestinal clostridial infection with apremilast $30 \mathrm{mg}$ BID), and 3 were reported after Week 24 (pneumonia and appendicitis in 1 patient each receiving apremilast $20 \mathrm{mg}$ $\mathrm{BID}$, and gastroenteritis in 1 patient receiving apremilast 30 mg BID). Only the gastrointestinal clostridial infection and 2 cases of pneumonia were considered to be treatment-related. All patients with serious infections recovered after standard courses of antibiotic treatment. The patient with clostridial infection discontinued from the study because of the event. The patient with pneumonia receiving apremilast $30 \mathrm{mg}$ BID during the placebo-controlled period had treatment interrupted, but remained in the study. In the remaining patients, no action with study medication was taken. One skin malignancy (squamous cell carcinoma) was identified during the 52-week period. No cases of lym- phoma, de novo tuberculosis, or tuberculosis reactivations were reported for the 52-week period.

Six patients discontinued because of SAE (weeks 0 to 52): 2 placebo patients (abnormal thinking and prostate cancer), 1 patient receiving apremilast $20 \mathrm{mg}$ BID (acute myocardial infarction), and 3 patients receiving apremilast $30 \mathrm{mg}$ BID (deep vein thrombosis and acute hypotension, hypertensive crisis, and gastrointestinal clostridial infection). One death occurred on Day 73 (placebo-controlled phase) in a 52-year-old woman receiving apremilast $20 \mathrm{mg}$ BID plus MTX. The primary cause of death was multiorgan failure secondary to preexisting Vitamin $\mathrm{B}_{12}$ deficiency and was considered unrelated to study medication by the investigator. No other deaths were reported.

Marked laboratory abnormalities, as well as shifts outside the normal range, were infrequent (Table 2), with 1 
or 2 patients experiencing marked increases in alanine aminotransferase $(\mathrm{n}=2$, apremilast $30 \mathrm{mg}$ BID) or creatinine ( $\mathrm{n}=1$, apremilast $20 \mathrm{mg}$ BID), or marked decreases in hemoglobin $(\mathrm{n}=2$, apremilast $30 \mathrm{mg}$ BID). Marked abnormal liver function tests or reports of $\mathrm{AE}$ related to liver function test abnormalities were infrequent and asymptomatic, resolved despite continuation of apremilast, and at times were caused by alternative etiology (e.g., concomitant viral gastroenteritis or concomitant medication known to cause liver function test elevation). No marked abnormalities in leukocytes, neutrophils, or platelets were reported.

Weight decrease was reported as an $\mathrm{AE}$ in a small proportion of patients: $0.0 \%$ (placebo), $1.8 \%$ (apremilast 20 $\mathrm{mg}$ BID), and $1.8 \%$ (apremilast $30 \mathrm{mg}$ BID) during the placebo-controlled period, and $1.6 \%$ (apremilast $20 \mathrm{mg}$ BID) and $2.0 \%$ (apremilast $30 \mathrm{mg}$ BID) during the apremilast-exposure period. Additional weight-change analyses were conducted using observed weight measurements collected prospectively at selected study visits. At Week 52, the mean change in weight from baseline was $0.91 \mathrm{~kg}$ with apremilast $20 \mathrm{mg}$ BID and $-1.79 \mathrm{~kg}$ with apremilast $30 \mathrm{mg}$ BID. The majority of patients maintained their weight within $5 \%$ of baseline. Weight loss $>5 \%$ was observed in $15.8 \%$ of patients receiving apremilast $20 \mathrm{mg}$ BID and $17.2 \%$ receiving apremilast $30 \mathrm{mg}$ BID.

\section{DISCUSSION}

PsA is a serious chronic immune disease requiring longterm treatment $3,4,5,6,7$. Successes achieved with currently available agents have raised the bar such that the goal for treatment is as low a state of disease activity as possible for all patients. Because conventional DMARD and biologic agents are not effective or tolerated in all patients, additional therapies are indicated $8,9,10,11,12,13$. Based on shorter-term data, apremilast showed the potential to offer patients with active PsA an additional treatment option.

The current report demonstrated that, in patients continuously treated with apremilast, response to treatment was maintained for up to 52 weeks across efficacy variables, including measures of disease activity, physical function, associated psoriasis, health-related quality of life, and fatigue. In patients with enthesitis or dactylitis at baseline who received active treatment through 52 weeks, apremilast demonstrated improvements from baseline in enthesitis and dactylitis at Week 52.

Apremilast demonstrated an acceptable safety profile following up to 52 weeks of administration at either dose and continued to be generally well tolerated. The safety profile was similar to that observed in the placebo-controlled phase, with no notable changes in the nature, incidence, or severity of AE, SAE, or AE leading to discontinuation following longterm treatment after Week 24. The incidences of diarrhea and nausea were generally highest during the first 2 weeks of dosing, with the majority resolving within 1 month despite continued therapy and without medical intervention. Individual, markedly abnormal values were reported infrequently and were limited to isolated (single values) excursions outside the normal range, and did not indicate a need for routine laboratory monitoring with apremilast administration.

These observed, longer-term findings may be limited in that the efficacy results can be biased because patients not responding to treatment are most likely to discontinue the study. The 52-week analyses included only those patients remaining in the trial, with no imputation for missing data. In this 52-week study, $6.8 \%$ of patients randomized to apremilast at baseline discontinued because of lack of efficacy, and $8.0 \%$ discontinued because of AE. Treatment compliance was $>96 \%$ during the period 0 to 24 weeks and 24 to 52 weeks. Another limitation is the lack of placebo arm extension beyond Week 24. Although typical of longterm clinical trial followup, without the inclusion of a placebo during weeks 24 to 52, it may be difficult to assess whether patients would have improved on their own given the natural resolution of PsA episodic flares that may occur over time.

PALACE 1 is the first study in the PALACE apremilast clinical trial program, which is composed of 4 phase III randomized, placebo-controlled trials with longterm, open-label extensions up to 5 years. Our results represent the first 52-week data of apremilast in patients with active PsA and demonstrate maintenance of response across multiple domains of PsA with up to 52 weeks of treatment.

\section{ACKNOWLEDGMENT}

We thank Maricar Postaski (data management, clinical operations), Peter Maes, Colleen Newman, Rosemary Petric, Yufang Lu, and Adele Vessey (clinical research), Elisabeth Kurkimilis (clinical operations), Andrew Wang (programming), and Xiaojiang Zhan (statistics) of Celgene Corporation for their contributions to the manuscript. The authors received editorial support funded by Celgene Corporation, from Jennifer Schwinn, RPh, and Peloton Advantage LLC.

\section{REFERENCES}

1. Schafer P. Apremilast mechanism of action and application to psoriasis and psoriatic arthritis. Biochem Pharmacol 2012; 83:1583-90

2. Kavanaugh A, Mease PJ, Gomez-Reino JJ, Adebajo AO, Wollenhaupt J, Gladman DD, et al. Treatment of psoriatic arthritis in a phase 3 randomised, placebo-controlled trial with apremilast, an oral phosphodiesterase 4 inhibitor. Ann Rheum Dis 2014;73:1020-6.

3. Gladman DD, Antoni C, Mease P, Clegg DO, Nash P. Psoriatic arthritis: epidemiology, clinical features, course, and outcome. Ann Rheum Dis 2005;64 Suppl 2:ii14-7.

4. Strand V, Sharp V, Koenig AS, Park G, Shi Y, Wang B, et al. Comparison of health-related quality of life in rheumatoid arthritis, psoriatic arthritis and psoriasis and effects of etanercept treatment. Ann Rheum Dis 2012;71:1143-50.

5. Singh JA, Strand V. Spondyloarthritis is associated with poor function and physical health-related quality of life. J Rheumatol 2009;36:1012-20

Personal non-commercial use only. The Journal of Rheumatology Copyright (C) 2015. All rights reserved. 
6. Zhu TY, Tam LS, Leung YY, Kwok LW, Wong KC, Yu T, et al. Socioeconomic burden of psoriatic arthritis in Hong Kong: direct and indirect costs and the influence of disease pattern. J Rheumatol 2010;37:1214-20.

7. Sokoll KB, Helliwell PS. Comparison of disability and quality of life in rheumatoid and psoriatic arthritis. J Rheumatol 2001;28:1842-6.

8. Kingsley GH, Kowalczyk A, Taylor H, Ibrahim F, Packham JC, McHugh NJ, et al. A randomized placebo-controlled trial of methotrexate in psoriatic arthritis. Rheumatology 2012;51:1368-77.

9. Fraser AD, van Kuijk AW, Westhovens R, Karim Z, Wakefield R, Gerards AH, et al. A randomised, double blind, placebo controlled, multicentre trial of combination therapy with methotrexate plus ciclosporin in patients with active psoriatic arthritis. Ann Rheum Dis 2005;64:859-64.

10. Salvarani C, Macchioni P, Olivieri I, Marchesoni A, Cutolo M, Ferraccioli G, et al. A comparison of cyclosporine, sulfasalazine, and symptomatic therapy in the treatment of psoriatic arthritis. J Rheumatol 2001;28:2274-82.

11. Menter A, Gottlieb A, Feldman SR, Van Voorhees AS, Leonardi $\mathrm{CL}$, Gordon KB, et al. Guidelines of care for the management of psoriasis and psoriatic arthritis: section 1. Overview of psoriasis and guidelines of care for the treatment of psoriasis with biologics. J Am Acad Dermatol 2008;58:826-50.

12. Menter A, Korman NJ, Elmets CA, Feldman SR, Gelfand JM, Gordon KB, et al. Guidelines of care for the management of psoriasis and psoriatic arthritis: section 4. Guidelines of care for the management and treatment of psoriasis with traditional systemic agents. J Am Acad Dermatol 2009;61:451-85.

13. Gniadecki R, Kragballe K, Dam TN, Skov L. Comparison of drug survival rates for adalimumab, etanercept and infliximab in patients with psoriasis vulgaris. Br J Dermatol 2011;164:1091-6. 
APPENDIX 1. Baseline demographics and clinical characteristics in PALACE 1: intent-to-treat population $(\mathrm{n}=504 *)$. Values are mean $(\mathrm{SD})$ or $\mathrm{n}(\%)$.

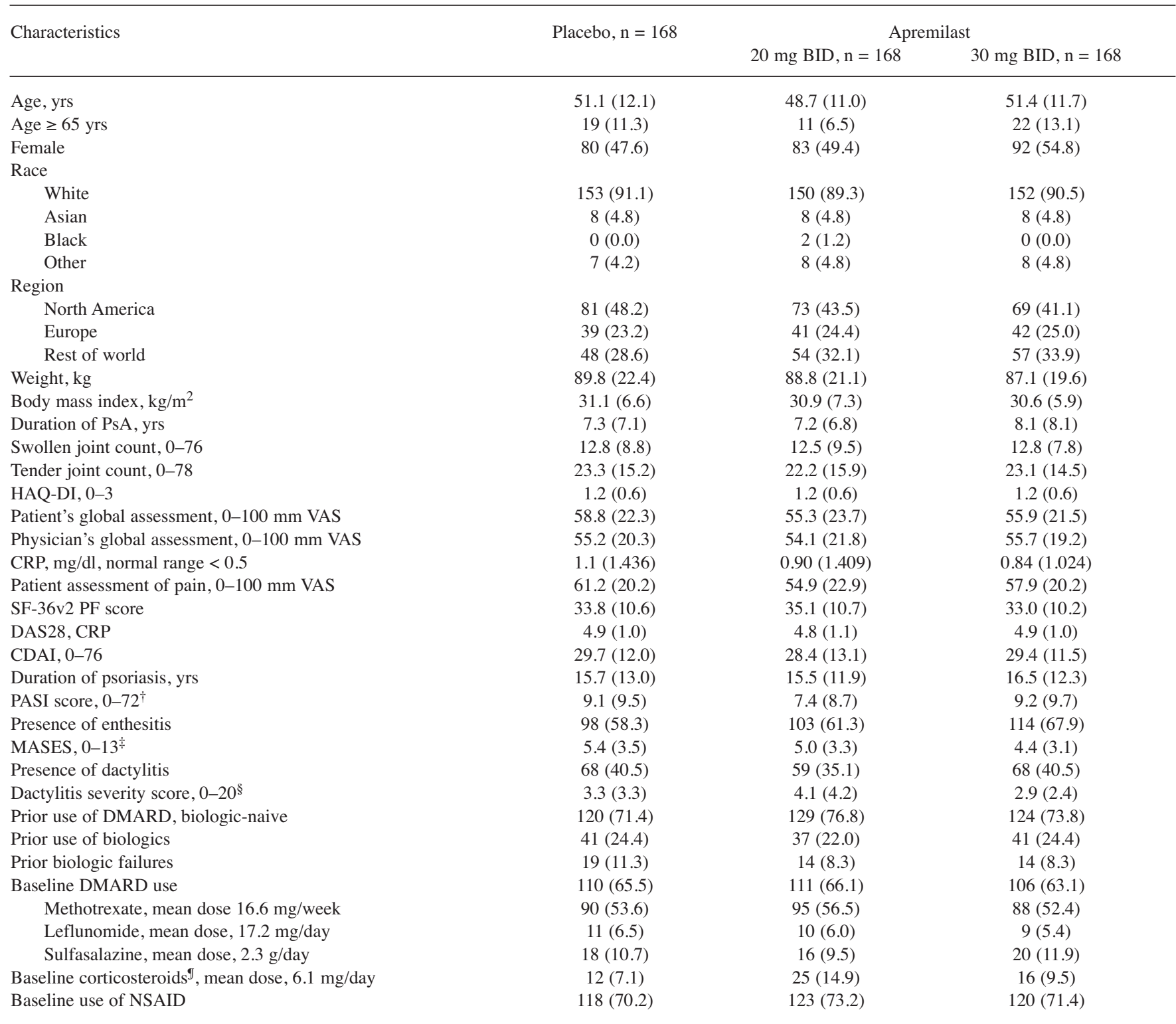

From Kavanaugh A, et al. Ann Rheum Dis 2014;73:1020-6, with permission. * The n reflects the no. randomized patients; actual no. patients available for each endpoint may vary. ${ }^{\dagger}$ Examined among patients who had body surface area $\geq 3 \%$ affected at baseline. ${ }^{\ddagger}$ Examined among patients who had enthesitis at baseline. ${ }^{\S}$ Examined among patients who had dactylitis at baseline. I Prednisone $\leq 10 \mathrm{mg} /$ day (or equivalent). PsA: psoriatic arthritis; HAQ-DI: Health Assessment Questionnaire-Disability Index; VAS: visual analog scale; CRP: C-reactive protein; SF-36v2 PF: Medical Outcomes Study Short Form-36 health survey version 2 Physical Functioning domain; DAS28: 28-joint Disease Activity Score; CDAI: Clinical Disease Activity Index; PASI: Psoriasis Area and Severity Index; MASES: Maastricht Ankylosing Spondylitis Enthesitis Score; DMARD: disease-modifying antirheumatic drugs; NSAID: nonsteroidal antiinflammatory drugs. 
APPENDIX 2. Efficacy endpoints at Week 52 in PALACE 1 (value at timepoint, data as observed*). The $\mathrm{n}$ reflects the no. patients who completed 52 weeks; actual no. patients available for each endpoint may vary. Values are $\mathrm{n} / \mathrm{m}(\%)$ or mean (SD).

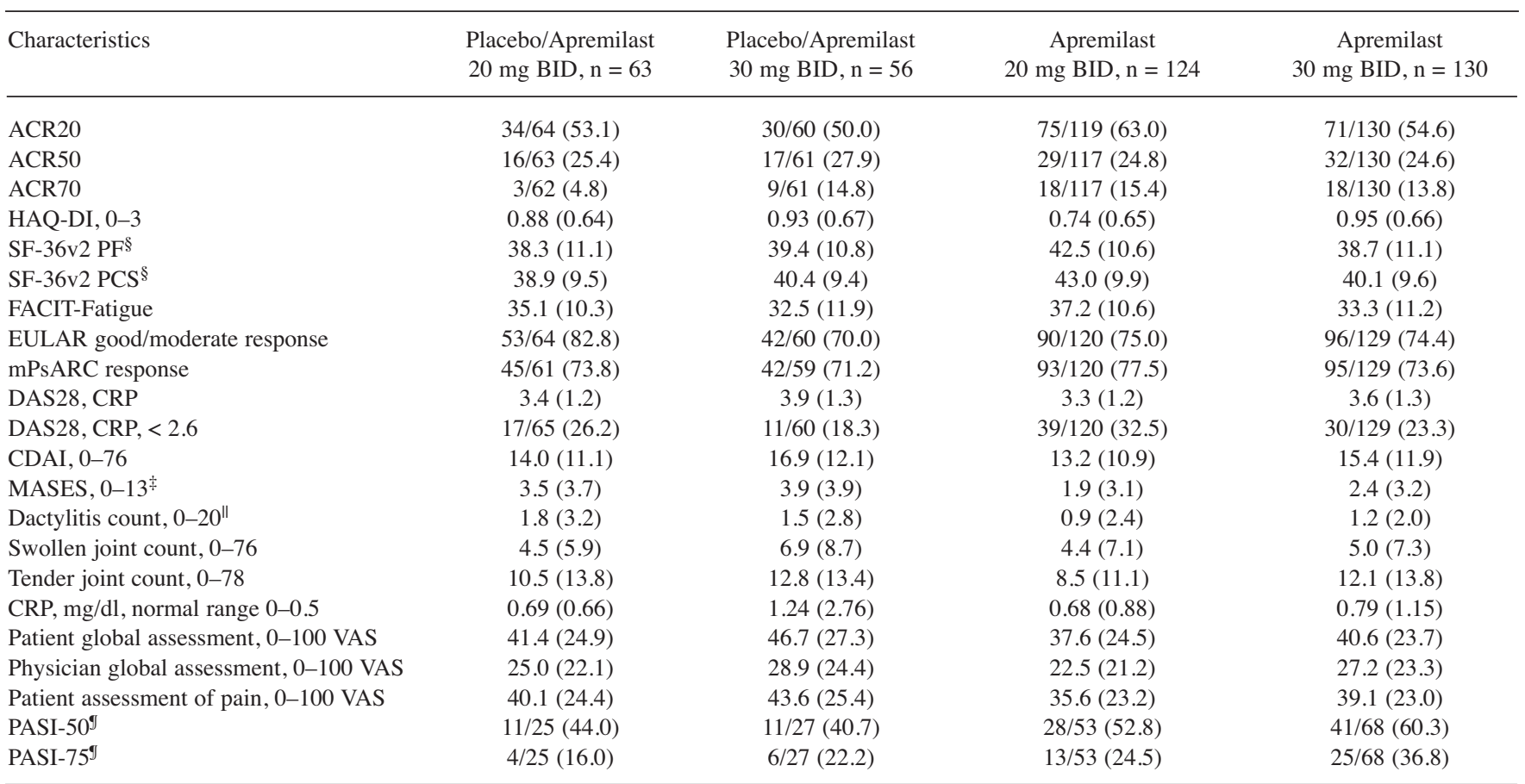

\footnotetext{
* Data as observed. Based on patients randomized to apremilast: placebo/apremilast $20 \mathrm{mg}$ BID and placebo/apremilast $30 \mathrm{mg}$ BID groups include patients who were randomized to placebo at baseline and re-randomized to apremilast $20 \mathrm{mg}$ BID and apremilast $30 \mathrm{mg}$ BID, respectively, at Weeks 16 or 24 ; apremilast $20 \mathrm{mg}$ BID and apremilast $30 \mathrm{mg}$ BID groups include patients randomized to the respective regimen at baseline. ${ }^{\S}$ Increase indicates improvement. ¥ Examined among patients with enthesitis at baseline and having data at Week 52 (placebo/apremilast $20 \mathrm{mg}$ BID: $\mathrm{n}=36$; placebo/apremilast $30 \mathrm{mg}$ BID: $\mathrm{n}=36$; apremilast $20 \mathrm{mg}$ BID: $\mathrm{n}=69$; apremilast $30 \mathrm{mg}$ BID: $\mathrm{n}=89$ ). " Examined among patients with dactylitis at baseline and having data at Week 52 (placebo/apremilast 20 mg BID: $\mathrm{n}=23$; placebo/apremilast 30 mg BID: $\mathrm{n}=26$; apremilast $20 \mathrm{mg}$ BID: $\mathrm{n}=48$; apremilast $30 \mathrm{mg}$ BID: $\mathrm{n}=49$ ). ${ }^{\mathfrak{J}}$ Examined among patients with psoriasis involving body surface area $\geq 3 \%$ at baseline. $\mathrm{n} / \mathrm{m}$ : number of responders/number of patients with sufficient data for evaluation; ACR20/50/70: 20\%/50\%/70\% improvement in modified American College of Rheumatology response criteria; HAQ-DI: Health Assessment Questionnaire-Disability Index; SF-36v2 PF: Medical Outcomes Study Short Form-36 health survey version 2 Physical Functioning domain; PCS: physical component summary score; FACIT-Fatigue: Functional Assessment of Chronic Illness Therapy-Fatigue; EULAR: European League Against Rheumatism; mPsARC: modified psoriatic arthritis response criteria; DAS28: 28-joint Disease Activity Score (using CRP as acute-phase reactant); CRP: C-reactive protein; CDAI: Clinical Disease Activity Index; MASES: Maastricht Ankylosing Spondylitis Enthesitis Score; VAS: visual analog scale; PASI-50/75: 50\%/75\% reduction from baseline Psoriasis Area and Severity Index score.
} 